Pontifícia Universidade $_{\text {Do Rio de Janeiro }}$

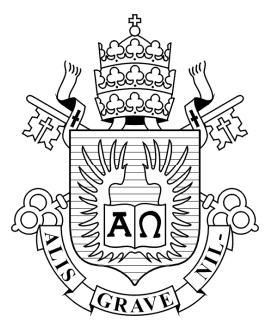

Esteban Maldonado Quispe

Análise Dinâmica de um Aterro Reforçado com Geossintéticos

Dissertação de Mestrado

Dissertação apresentada como requisito parcial para obtenção do título de Mestre pelo Programa de PósGraduação em Engenharia Civil da PUC-Rio. Área de concentração: Geotecnia

Orientador: Celso Romanel 


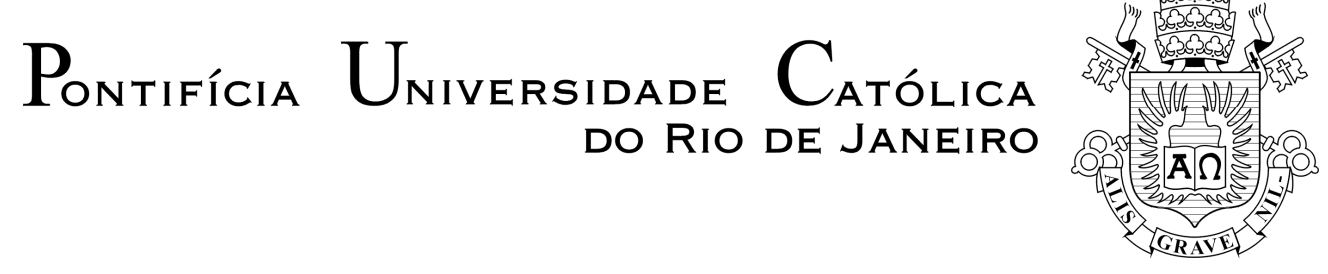

Esteban Maldonado Quispe

\title{
Análise Dinâmica de um Aterro Reforçado com Geossintéticos
}

Dissertação apresentada como requisito parcial para obtenção do título de Mestre pelo Programa de PósGraduação em Engenharia Civil da PUC-Rio. Aprovada pela Comissão Examinadora abaixo assinada.

\author{
Celso Romanel \\ Orientador \\ Departamento de Engenharia Civil - PUC-Rio \\ João Luis Pascal Roehl \\ Departamento de Engenharia Civil - PUC-Rio
}

Michéle Dal Toé Casagrande Departamento de Engenharia Civil - PUC-Rio

José Eugênio Leal Coordenador Setorial do Centro Técnico Científico da PUC-Rio

Rio de Janeiro, 01 de Agosto de 2008 
Todos os direitos reservados. É proibida a reprodução total ou parcial do trabalho sem autorização da universidade, do autor e do orientador.

\section{Esteban Maldonado Quispe}

Graduou-se em Engenharia Minas em 1991 pela Universidad Nacional del Centro del Peru (UNCP) e em Engenharia Civil em 2002 pela Universidad Peruana Los Andes (UPLA). Ingressou em 2006 no curso de Mestrado em Engenharia Civil da Pontifícia Universidade Católica de Rio de Janeiro, na área de Geotecnia, onde desenvolveu dissertação de mestrado na linha de pesquisa em geomecânica computacional.

Ficha Catalográfica

Maldonado Quispe, Esteban

Análise dinâmica de um aterro reforçado com geossintéticos / Esteban Maldonado Quispe; orientador: Celso Romanel. - Rio de Janeiro, PUC, Departamento de Engenharia Civil, 2008.

v.,134 f. : il. ; $29.7 \mathrm{~cm}$.

Dissertação (mestrado) - Pontifícia Universidade Católica do Rio de Janeiro, Departamento de Engenharia Civil.

Inclui referências bibliográficas.

1. Engenharia civil - Tese. 2. Geossintéticos. 3. Análise numérica. 4. Aterro. 5. Solo reforçado. 6. Análise dinâmica. I. Romanel, Celso. II. Pontifícia Universidade Católica do Rio de Janeiro. Departamento de Engenharia Civil. III. Título.

CDD: 624 


\section{Agradecimentos}

A Deus, por conduzir-me por caminhos de sabedoria e com Sua benção.

Aos meus queridos irmãos, Celestino, Pablo, Guillermo e Martha, pelo amor e apoio moral mesmo à distância.

À memória de meus pais que sempre estão em minha mente e no meu coração.

Ao Professor Celso Romanel, por sua orientação, paciência e conhecimentos transmitidos durante a elaboração deste trabalho, meus mais sinceros agradecimentos.

A meus professores Mohamed Mehdi Hadi (UPLA-Perú) e Orison Delzo Salomé (UNCP-Perú) por seu apoio moral para tornar este mestrado realidade.

À Paola Regina e Vivian Rodrigues Marchesi pelas respostas às minhas questões e pela amizade brindada.

Ao Denys Parra, por seu apoio na elaboração deste trabalho.

Aos meus amigos e colegas da PUC-Rio, pelo carinho e amizade.

Aos funcionários e a todos os professores do Departamento de Engenharia Civil da PUC-Rio.

À Pontifícia Universidade Católica do Rio de Janeiro (PUC-Rio) por dar-me a valiosa oportunidade de ter sido aluno desta grande instituição.

Ao CNPq e À CAPES pela concessão da bolsa de estudos que me possibilitou o suporte financeiro durante minha estada no Brasil. 


\section{Resumo}

Maldonado, Esteban Quispe. Romanel, Celso (Orientador). Análise Dinâmica de um Aterro Reforçado com Geossintéticos. Rio de Janeiro, 2008. 134p. Dissertação de Mestrado - Departamento de Engenharia Civil, Pontifícia Universidade Católica do Rio de Janeiro.

Este trabalho tem como objetivo analisar a resposta sísmica do talude de um aterro $\left(10,40 \mathrm{~m}\right.$ de altura e $76^{\circ}$ de inclinação), reforçado com geossintéticos (09 camadas de reforço horizontal com $10 \mathrm{~m}$ de comprimento) localizada em zona de atividade sísmica, no Peru. Os aspectos investigados compreendem o estudo da estabilidade de taludes sob condição estática, a resposta dinâmica da estrutura, a influência das condições de contorno, do tipo de amortecimento do solo e do ângulo de atrito do solo que forma o aterro aterro. As análises dinâmicas foram realizadas utilizando o programa computacional FLAC (ITASCA, 2005), com representação dos reforços geossintéticos como elementos de cabo. O comportamento mecânico do material de rejeito foi simulado através do modelo elastoplástico de Mohr-Coulomb, considerando tanto o amortecimento de Rayleigh (dependente da freqüência), quanto o amortecimento histerético (dependente da deformação cisalhante do solo), com o objetivo de verificar os efeitos na resposta dinâmica do aterro e na distribuição das cargas máximas nos reforços. Um melhor entendimento de comportamento de taludes reforçados, principalmente sob ação de carregamentos sísmicos, é essencial para um adequado projeto de engenharia, tanto em termos técnicos quanto econômicos, em diversos países andinos da América do Sul.

\section{Palavras-chave}

Geossintéticos, análise numérica, aterro, solo reforçado, análise dinâmica. 


\section{Abstract}

Maldonado, Esteban Quispe. Romanel, Celso (advisor). Dynamic Analysis of a Geosynthetic Reinforced Embankment. Rio de Janeiro, 2008. 134p. M.Sc. Thesis - Department of Civil Engineering, Pontifícia Universidade Católica do Rio de Janeiro.

The main objective of this research is to investigate the seismic response of a soil slope reinforced with geosynthetics, located in an active seismic region of Peru. The $10.40 \mathrm{~m}$ high slope was reinforced with 9 horizontal layers of geosynthetics $10 \mathrm{~m}$ long. The aspects studied in this work are related to the slope static stability, the dynamic response of the embankment under seismic excitation, the effects of the boundary conditions and the different types of mechanical damping, the influence of the friction angle of the soil that forms the embankment. The seismic analysis was carried out with the computational program FLAC, where the reinforcement layers were represented by means of cable elements. The soil mechanical behavior was simulated through the MohrCoulomb elastoplastic constitutive model, considering both the frequencydependent Rayleigh damping and the hysteretic damping (dependent on the soil shear deformation) with the objective to understand the influence of all these variables on the dynamic response of the structure and on the distribution of traction forces along the reinforcements. A good knowledge about the mechanical behavior of soil reinforced structures is essential for an efficient engineering design, under the technical and economical points of view, mainly in the Andean countries of South America.

\section{Keywords}

Geosynthetics, numerical analysis, embankment, reinforced soil, dynamic analysis. 


\section{Sumário}

1. Introdução 19

1.1. Motivação e objetivos 19

1.2. Estrutura da dissertação 20

2. Revisão Bibliográfica 21

2.1. Introdução 21

2.2. Tectônica de placas $\quad 21$

2.2.1. Deriva dos continentes 21

2.2.2. Sismicidade no Peru 25

2.3. Propagação de ondas planas de tensão 26

2.4. Solos reforçados com geossintéticos $\quad 29$

2.4.1. Geossintéticos 31

2.4.1.1. Geotêxteis 31

2.4.1.2. Geogrelhas 33

2.4.2. Desempenho de solos reforçados sob carregamentos sísmicos 33

2.4.3. Mecanismos de ruptura em solos reforçados 36

2.5. Estabilidade de estruturas de contenção com solos reforçados 38

2.5.1. Estabilidade externa 38

2.5.2. Estabilidade interna 38

2.5.3. Análise estática de taludes de solo reforçado 40

2.5.4. Análise dinâmica de taludes de solo reforçado 42

2.6 Modelo linear equivalente 45

2.6.1. Estimativa de $G_{\max } \quad 47$

2.6.2. Curva de redução do módulo cisalhante 49

2.6.3. Razão de amortecimento 50

3. Modelagem numérica com programa FLAC 53

3.1. Descrição geral do programa FLAC 53

3.2. Modelagem do aterro 56

3.3. Modelagem do reforço $\quad 57$

3.3.1. Comportamento axial $\quad 57$

3.3.2. Comportamento cisalhante na interface solo-reforço 58 
3.3.3. Propriedades do reforço 60

3.4. Aspectos da modelagem dinâmica 60

3.4.1. Contornos silenciosos 60

3.4.2. Contornos de campo livre 62

3.4.3. Transmissão de ondas 64

3.4.4. Filtragem do registro sísmico 64

3.4.5. Correção da linha base 65

3.4.6. Carregamento dinâmico 66

3.4.7. Amortecimento mecânico 68

3.4.7.1. Amortecimento de Rayleigh 68

3.4.7.2. Amortecimento histerético 71

3.4.7.3. Amortecimento local 73

4. Estabilidade estática do aterro reforçado 75

4.1. Introdução $\quad 75$

4.2. Propriedades dos materiais $\quad 75$

4.2.1. Propriedades do solo $\quad 75$

4.2.2. Propriedades do reforço e interface 76

4.3. Discretização 77

4.4. Estabilidade estática do aterro 79

4.5. Deslocamentos laterais e forças nos reforços 81

5. Análise dinâmica do aterro reforçado 84

5.1. Sismo de projeto

5.2. Perfil do solo $\quad 86$

5.3. Análise 1D com o programa SHAKE 89

5.4. Análise 1D com o programa FLAC e amortecimento histerético 90

5.5. Modelagem dinâmica do aterro reforçado com FLAC 93

5.5.1. Propriedades dos solos e reforços 93

5.5.2. Malha, condições de contorno, tamanho de zonas 93

5.5.3. Filtragem 95

5.5.4. Correção da linha base 96

5.5.5. Carregamento dinâmico 99

5.5.6. Freqüência fundamental do sistema 101

5.6. Resultados do análise dinâmica do aterro reforçado 103

5.6.1. Influência dos contornos 103

5.6.2. Influência de amortecimento mecânico 107 
5.6.2.1. Amortecimento de Rayleigh 107

5.6.2.2. Amortecimento histerético 107

5.6.2.3. Amortecimento local 111

5.7. Comparações dos resultados 112

5.8. Influência do ângulo de atrito no amortecimento histerético 115

6. Conclusões e sugestões 117

$\begin{array}{ll}\text { Referências bibliográficas } & 120\end{array}$

$\begin{array}{lr}\text { Anexos } & 127\end{array}$ 


\section{Lista de figuras}

Figura 2.1 - Teoria da deriva dos continentes segundo Taylor (1910), Wegener

Figura 2.2 - Placas tectônicas principais (USGS, Washington, 2001).

Figura 2.3 - Elementos característicos de um terremoto.

Figura 2.4 - Esquema de zona subducção no Peru, movimentos de placas e distribuição de sismos (H.Talavera, IGP,1993). 25

Figura 2.5 - Deformações produzidas por ondas P (apud Kramer, 1996) 27

Figura 2.6 - Deformações produzidas por ondas SV (apud Kramer,1996). 27

Figura 2.7 - Deformações causadas por ondas superficiais: (a) ondas Rayleigh;

(b) ondas de Love (apud Kramer, 1996).

Figura 2.8 - Relação entre $C_{R}$, Cs, e $\mathrm{Cp}$ em função do coeficiente de Poisson (apud Richard \& Woods 1970).

Figura 2.9 - Ondas sísmicas registradas a 10.000 km do epicentro: a) sismo de foco profundo; b) sismo de foco superficial (apud Sauter, 1989).

29

Figura 2.10 - Aterro reforçado de 35m de altura na cidade de Taichung, Taiwan.

Figura 2.11 - Sistema de muro de contenção reforçado usando geossintéticos.

Figura 2.12 - Arranjo estrutural de geotêxteis.

Figura 2.13 - Exemplos de geogrelhas.

Figura 2.14 - Fissuração atrás dos reforços de comprimento curto, no topo do muro Valencia ( EUA), após terremoto de Northridge, em 1994 (Bathurst e Cai, 1995).

Figura 2.15 - Ruptura de paramento de blocos de concreto de muro reforçado com geossintéticos após terremoto Chi - Chi, de magnitude 7.3, em Tai Chung (Taiwan).

Figura 2.16 - Sistema de instrumentação com acelerômetros, potenciômetros e condição da face do modelo construído por Perez (1999).

Figura 2.17 - Mecanismo de reforço de estruturas de contenção em solos reforçados (apud Huasmann, 1990).

Figura 2.18 - Tensões principais em solos reforçados (apud Hausmann,1990). 38

Figura 2.19 - Modos de ruptura de estruturas em solo reforçado (apud Lee, 2000). 
Figura 2.20 - Zonas ativa e resistente (Ehrlich e Mitchell, 1994).

Figura 2.21 - Seção transversal da barragem de Lower San Fernando antes e após o sismo de 1971.

Figura 2.22 - Procedimento de dupla integração no tempo no método de Newmark (Smith, 1995).

Figura 2.23 - Comportamento cíclico típico dos solos (Kramer, 1996): a) Relação tensão-deformação cisalhante para o primeiro ciclo de carregamento. b) Variação da rigidez em função do nível de deformação por cisalhamento

Figura 2.24 - Variação do módulo de cisalhamento $\mathrm{K}_{2 \max }$ para areias com diferentes densidades relativas - Seed e Idriss (1970).

Figura 2.25 - Faixa de variação de $G / G_{\max }$ com a deformação cisalhante para areias (Seed e ldriss, 1970).

Figura 2.26 - Faixa de variação de $G / G_{\max }$ com a deformação cisalhante para pedregulhos (Seed e Idriss, 1970).

Figura 2.27 - Efeito do índice de plasticidade na curva de redução do módulo de cisalhamento de solos coesivos (Vucetic e Dobry,1991).

Figura 2.28 - Variação da razão de amortecimento para areias (Seed e Idriss, 1970).

Figura 2.29 - Comparação da variação da razão de amortecimento para solos com pedregulho e areias (Seed et al.., 1986).

Figura 2.30 - Efeito do índice de plasticidade nas curvas de variação da razão de amortecimento vs deformação cisalhante para solos coesivos (Vucetic e Dobry, 1991).

Figura 3.1 - Exemplo de modelagem no programa FLAC.

Figura 3.2 - Comportamento do material para elementos de cabo.

Figura 3.3 - Comportamento do material de interface.

Figura 3.4 - Modelo para análise sísmica de uma estrutura de superfície e com condição de contorno em campo livre.

Figura 3.5 - Processo de correção da linha base.

Figura 3.6 - Condições de contorno e carregamento dinâmico.

Figura 3.7 - Variação da razão de amortecimento crítica normalizada em relação à freqüência angular.

Figura 3.8 - Limite superior da curva de redução do modelo de cisalhamento para areias proposta por Seed \& Idriss(1970).

Figura 3.9 - Curvas de degradação de G no modelo linear equivalente implementado nos programas computacionais SHAKE e FLAC v.5. 
Figura 3.10 - Curvas de aumento da razão crítica de amortecimento no modelo linear equivalente implementado nos programas computacionais SHAKE e FLAC v.5

Figura 4.1 - Instalação de geogrelha e colocação de material de rejeito na construção do aterro reforçado (Peru).

Figura 4.2 - Construção da etapa final do aterro reforçado com geossintéticos na barragem de rejeitos III da mina San Rafael (Peru).

Figura 4.3 - Discretização adotada para análise estática.

Figura 4.4 - Análise de estabilidade do aterro sem reforço - contornos de máxima velocidade de deformação cisalhante e vetores de velocidade.

Figura 4.5 - Análise de estabilidade do aterro com reforço - contornos de máxima velocidade de deformação cisalhante.

Figura 4.6 - Variação de fator de segurança com a altura do talude com e sem reforço.

Figura 4.7 - (a) Deslocamentos horizontais na face do talude. (b) Tração máxima nos reforços de geossintético.

Figura 4.8 - Equilíbrio local de uma camada de reforço.

Figura 4.9 - Ábaco para projeto de taludes reforçados (R.I.Woods,1993).

Figura 5.1 - Curvas de isoacelerações para 10\% de excedência em 100 anos (Alva e Castillo, 1993), Peru.

Figura 5.2 - Registro de acelerações do terremoto de Moquegua de 23/06/2003.

Figura 5.3 - Registro normalizado das acelerações do terremoto de Moquegua de 23/06/2003 em relação à aceleração máxima de $0.19 \mathrm{~g}$ no embasamento rochoso.

Figura 5.4 - Material do rejeito: curvas de variação do módulo G e da razão de amortecimento para areias(Seed e Idriss, 1970; Idriss, 1990).

Figura 5.5 - Material de botafora: curvas médias de variação do módulo G e da razão de amortecimento para areias e pedregulhos.

Figura 5.6 - Amplificação da aceleração na profundidade de 12m (SHAKE). 89

Figura 5.7 - Relação da tensão versus deformação cisalhante do material da camada 3 do aterro (SHAKE).

Figura 5.8 - Modelo unidimensional utilizado no FLAC.

Figura 5.9 - Resposta das acelerações na profundidade de 12m (FLAC). 92

Figura 5.10 - Tensão cisalhante versus deformação cisalhante na camada de número 3, a $5 \mathrm{~m}$ de profundidade do topo do aterro (FLAC). 92

Figura 5.11 - Malha do modelo adotado no FLAC. 
Figura 5.12 - Modelo de aterro reforçado com materiais e condições de contorno indicados (FLAC). 95

Figura 5.13 - História de aceleração horizontal na fase intensa do sismo. $\quad 97$

Figura 5.14 - Espectro de potência do registro de acelerações da figura 5.13

(FLAC). $\quad 97$

Figura 5.15 - História de aceleração horizontal na fase intensa do sismo considerando filtro em $7.3 \mathrm{~Hz} . \quad 98$

Figura 5.16 - Espectro de potência do registro de acelerações da figura 5.15 considerando filtro em $7.3 \mathrm{~Hz}$. 98

Figura 5.17 - História dos deslocamentos com linha base corrigida e nãocorrigida (FLAC). $\quad 99$

Figura 5.18 - História das velocidades com linha base corrigida e não-corrigida (FLAC). $\quad 99$

Figura 5.19 - Ajuste necessário para concordar os registros de ondas de velocidade e de ondas de tensão cisalhante: (a) na base do modelo, em função dos deslocamentos horizontais; (b) na base do modelo, em função das velocidades horizontais.

101

Figura 5.20 - História das velocidades horizontais $(\mathrm{m} / \mathrm{s})$ não-amortecidas no ponto nodal $(15,15)$ usando o FLAC. 102

Figura 5.21 - Espectro de potência das velocidades horizontais não-amortecidas no ponto nodal $(15,15)$. Freqüência fundamental $=1.048 \mathrm{~Hz}$. 102

Figura 5.22 - Influência da introdução de contornos de campo livre: (a) na distribuição dos deslocamentos horizontais; (b) na distribuição de forças de tração nos reforços.

104

Figura 5.23 - Influência da consideração de contornos de campo livre no registro de velocidades do nó $(31,29)$, no topo do talude.

104

Figura 5.24 - Contornos de deslocamentos horizontais ao final da excitação sísmica. Análise não-amortecida.

Figura 5.25 - Contorno de máximos incrementos de deformação cisalhante ao final da excitação sísmica. Análise não-amortecida.

106

Figura 5.26 - Distribuição de esforços de tração nos reforços do aterro ao final da excitação sísmica. Análise não-amortecida.

106

Figura 5.27 - Contornos de deslocamentos horizontais ao final da excitação sísmica. Amortecimento de Rayleigh.

107

Figura 5.28 - Contornos de incrementos máximos de deformação cisalhante ao final da excitação sísmica. Amortecimento de Rayleigh. 
Figura 5.29 - Forças máximas de tração nas camadas de reforço do aterro ao final da excitação sísmica. Amortecimento de Rayleigh.

Figura 5.30 - Contornos de deslocamentos horizontais ao final da excitação sísmica. Amortecimento histerético e de Rayleigh (0.5\%).

Figura 5.31 - Contornos de incrementos máximos de deformação cisalhante, ao final da excitação sísmica. Amortecimento histerético e de Rayleigh (0.5\%).

Figura 5.32 - Forças máximas de tração nas camadas de reforço ao final da excitação sísmica. Amortecimento histerético e de Rayleigh (0.5\%) 116

Figura 5.33 - Contornos de deslocamentos horizontais ao final da excitação sísmica. Amortecimento local.

Figura 5.34 - Contornos de incrementos máximos de deformação cisalhante, ao final da excitação sísmica. Amortecimento local.

Figura 5.35 - Forças máximas de tração nas camadas de reforço ao final da excitação sísmica. Amortecimento local.

Figura 5.36 - Influência do amortecimento mecânico no deslocamento horizontal da face do aterro reforçado.

Figura 5.37 - Influência do amortecimento mecânico na força de tração máxima no aterro reforçado.

Figura 5.38 - História dos deslocamentos no topo do aterro reforçado (nó 31,29).

Figura 5.39 - Influência do ângulo de atrito nos deslocamentos horizontais da face do talude do aterro reforçado.

Figura 5.40 - Influência de ângulo de atrito nas forças de tração máxima nos reforços do aterro. 


\section{Lista de tabelas}

Tabela 2.1 - Tipos de geossintético e principais funções (Koerner,1998)

Tabela 2.2 - Resumo do desempenho de estruturas de solo reforçado sob ação sísmica (Nova - Roessing, 1999)

Tabela 2.3 - Fator de segurança mínimo em talude de solo reforçado (Holtz et al., 1997)

Tabela 2.4 - Estimativa de $\mathrm{K}_{2, \max }$ (Seed e Idriss, 1970)

Tabela 3.1 - Modelos constitutivos disponíveis no programa FLAC v.5 55

Tabela 3.2 - Valores típicos da razão de amortecimento crítico 70

Tabela 4.1 - Propriedades da fundação e solo de aterro 76

Tabela 4.2 - Características do rejeito do aterro 76

Tabela 5.1 - Valores representativos de critérios de projeto considerando movimentos sísmicos $\quad 84$

Tabela 5.2 - Perfil de depósito do solo e respectivas propriedades $\quad 87$

Tabela 5.3 - Propriedades do solo de fundação e aterro 93

Tabela 5.4 - Propriedades das geogrelhas 93

Tabela 5.5 - Cálculo de tamanho máximo da zona (elemento) 95 


\section{Lista de símbolos}

\begin{tabular}{|c|c|}
\hline$A$ & Área da seção transversal do reforço \\
\hline$A_{\text {laço }}$ & Àrea do laço de histerese \\
\hline$B$ & Largura do aterro \\
\hline$C_{p}$ & Velocidade de onda primária \\
\hline$C_{s}$ & Velocidade de onda secundária \\
\hline$C_{R}$ & Velocidade de onda Rayleigh \\
\hline C & Coesão \\
\hline$C_{\text {comp }}$ & Coesão do material compósito \\
\hline$D_{r}$ & Densidade relativa \\
\hline$E$ & Módulo de Young \\
\hline FS & Fator de segurança \\
\hline Fs & $\begin{array}{l}\text { Força cisalhante desemvolvida ao longo da interface } \\
\text { reforço-solo }\end{array}$ \\
\hline$F i$ & Força nodal \\
\hline$F i j(\omega)$ & Função de transferencia entre camadas i e j \\
\hline$f$ & Freqüência \\
\hline G & Módulo de cisalhamento \\
\hline$G_{\max }$ & Módulo de cisalhamento máximo \\
\hline$G_{\mathrm{sec}}$ & Módulo de cisalhamento secante \\
\hline $\mathrm{H}$ & Altura de aterro \\
\hline $\mathrm{J}$ & Rigidez do reforço \\
\hline $\mathrm{K}$ & Módulo de deformação volumétrica \\
\hline$K_{o}$ & Coeficiente de empuxo \\
\hline$K_{\text {bond }}$ & Rigidez cisalhante da interface \\
\hline$k_{s}$ & Rigidez cisalhante \\
\hline$k_{n}$ & Rigidez normal \\
\hline$L$ & Comprimento da zona reforçada \\
\hline$l_{o}$ & Comprimento inserido na zona resistente \\
\hline$n_{i}$ & Vetor unitário \\
\hline
\end{tabular}




\begin{tabular}{|c|c|c|}
\hline & $P$ & Poropressão \\
\hline & $\mathrm{P}_{\mathrm{a}}$ & Pressão atmosférica \\
\hline & $\mathrm{P}_{\mathrm{y}}$ & Límite de escoamento \\
\hline & $\mathrm{r}_{\mathrm{a}}$ & Raio do círculo a \\
\hline & $S_{h}$ & Espaçamento horizontal \\
\hline & $S_{v}$ & Espaçamento vertical \\
\hline & $S_{\text {bond }}$ & Coesão da argamassa \\
\hline & $S_{\text {friction }}$ & Ângulo de atrito da argamassa \\
\hline & $S^{(s)}$ & Valor inicial da tensão \\
\hline & $\mathrm{T}$ & Resistência ao cisalhamento do solo \\
\hline & $\operatorname{tn}$ & Tensão normal ao contorno \\
\hline & ts & Tensão cisalhante ao contorno \\
\hline & $T_{y}$ & Resistência ao escoamento do solo \\
\hline$\frac{1}{8}$ & $T_{\text {pullout }}$ & Resistência ao arrancamento do reforço \\
\hline 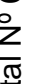 & $u_{c}$ & Deslocamento axial do cabo \\
\hline 玄 & $u_{m}$ & Deslocamento axial do solo \\
\hline 焉 & $u_{i}^{(b)}$ & Vetor de velocidade do nó "b" \\
\hline 0 & $v_{n}$ & Componente da velocidade normal ao contorno \\
\hline 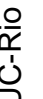 & $v_{s}$ & Componente da velocidade tangencial ao contorno \\
\hline & $v_{x}, v_{y}$ & Componentes das velocidades nas direções $\mathrm{x}$ e y \\
\hline & $V_{x}^{m}$ & $\begin{array}{l}\text { Velocidade na direção } x \text { do nó do contorno na malha } \\
\text { principal }\end{array}$ \\
\hline & $V_{y}^{m}$ & $\begin{array}{l}\text { Velocidade na direção y do nó do contorno na malha } \\
\text { principal }\end{array}$ \\
\hline & $V_{x}^{f f}$ & $\begin{array}{l}\text { Velocidade na direção } x \text { do nó do contorno na malha } \\
\text { de campo livre }\end{array}$ \\
\hline & $V_{y}^{f f}$ & $\begin{array}{l}\text { Velocidade na direção y do nó do contorno na malha } \\
\text { de campo livre }\end{array}$ \\
\hline & W & Peso de solo \\
\hline & $W_{d}$ & Energia dissipada no ciclo \\
\hline & $\mathrm{W}_{\mathrm{s}}$ & Energia de deformação máxima \\
\hline & $\omega_{i}$ & Freqüência angular \\
\hline
\end{tabular}




\begin{tabular}{|c|c|}
\hline$x^{(S)}, y^{(S)}$ & Coordenada do nó inicial \\
\hline$x^{(e)}, y^{(e)}$ & Coordenada do nó final \\
\hline$\rho$ & Massa específica \\
\hline$\xi_{i}$ & Razão de amortecimento crítico \\
\hline$\sigma_{m}^{\prime}$ & Tensão normal efetiva media \\
\hline$\gamma$ & Deformação cisalhante \\
\hline$\phi_{s g}$ & Ângulo de atrito na interface solo-geossinténtico. \\
\hline$\beta$ & Ângulo do talude \\
\hline$\Delta F$ & Incremento de força axial \\
\hline$\sigma_{x x}^{f f}$ & $\begin{array}{l}\text { Tensão horizontal média em nó do contorno da malha } \\
\text { de campo livre }\end{array}$ \\
\hline$\sigma_{x y}^{f f}$ & $\begin{array}{l}\text { Tensão cisalhante média em nó do contorno da malha } \\
\text { de campo livre }\end{array}$ \\
\hline$\sigma_{n}$ & Tensão normal aplicada \\
\hline$\sigma_{s}$ & Tensão cisalhante aplicada \\
\hline$\alpha, \beta$ & Coeficientes de Rayleigh \\
\hline$\varepsilon$ & Deformação axial \\
\hline$\lambda$ & Comprimento de onda \\
\hline$\alpha_{L}$ & Coeficiente de amortecimento local \\
\hline$\phi$ & Ângulo de atrito \\
\hline$\dot{u}_{i}^{(b)}$ & Vetor de velocidade no nó "b" \\
\hline$\psi$ & Ângulo de dilatância \\
\hline$\Delta S_{y}$ & Tamanho da zona vertical média nos nós do contorno \\
\hline$\gamma$ & Peso específico \\
\hline$\sigma_{z z}$ & Tensão fora-do-plano \\
\hline$\Delta l$ & $\begin{array}{l}\text { Comprimento do elemento na direção de propagação } \\
\text { da onda }\end{array}$ \\
\hline$\tau$ & Tensão cisalhante \\
\hline$v$ & Coeficiente de Poisson \\
\hline
\end{tabular}

